\title{
February 2003
}

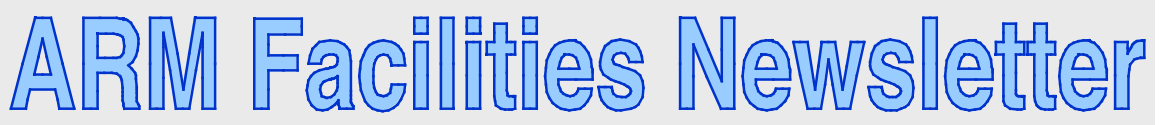

ANL/ ER/ NL $03-02$

\section{Cl oudiness Inter - comparison IOP}

Clouds are an important part of Earth's energy system. We take clouds for granted, but their role in weather and climate is considerable. Without clouds, life on Earth would be impossible. By helping to regulate surface temperatures, clouds establish livable conditions on the planet.

Clouds produced by water vapor condensation play a complicated role in our climate system. Clouds decrease the amount of sunlight received by Earth's surface. Decreased sunlight reduces evaporation driven by sunlight and thus reduces cloud formation. With fewer clouds, Earth receives more sunlight, which eventually increases evaporation and cloud production. On the other hand, clouds also trap longwave (infrared) radiation emitted by Earth, as does water vapor. This heating effect increases evaporation. In summary, cloud formation is a complex, self-regulating, cyclic process.

The SGP CART site is conducting a Cloudiness Inter-comparison IOP (intensive operational period) from
mid-February through mid-April. The central facility near Lamont, Oklahoma, currently is home to several cloud-measuring instruments. The process of measuring cloudiness has always been somewhat subjective. Cloud measurements were once made by solely human observation, but new technology enables instruments to view the sky and make the more objective cloud measurements needed by both operational and research meteorologists.

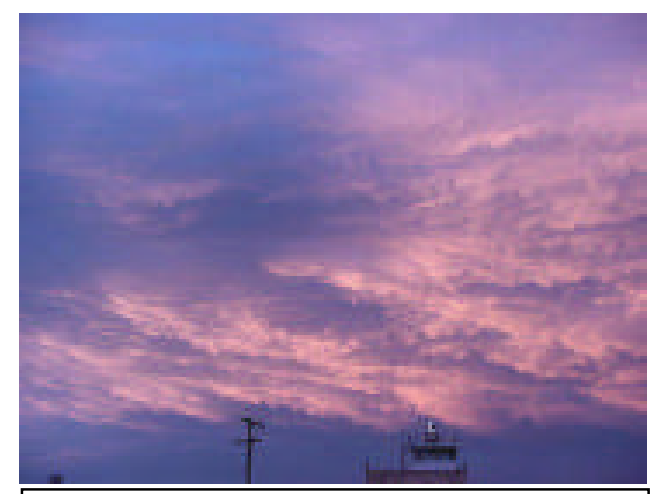

Figure 1. Clouds over the SGP CART site central facility. (ARM photo.)
ARM Facilities Newsletter is published by Argonne National Laboratory, a multiprogram laboratory operated by The University of Chicago under contract W-31-109Eng-38 with the U.S. Department of Energy.
Technical Contact: James C. Liljegren Phone: 630-252-9540

Email: jcliljegren@anl.gov

Editor: Donna J. Holdridge 
The SGP site currently operates eight different instruments that make cloudrelated measurements. Data are collected on cloud cover, cloud top and base location, cloud water vapor and liquid water, sunshine duration and amount, and cloud number and area. During the Cloudiness Inter-comparison IOP, three additional cloud-measuring instruments are being brought to the CART site to be tested and assessed against the current instruments.

Researchers are interested in testing whether the additional instruments can collect better data during nighttime hours, when visible light is not available for measurements.

One of the three additional instruments is a commercially produced analyzer called the Nephelo (from Groupe Leader,

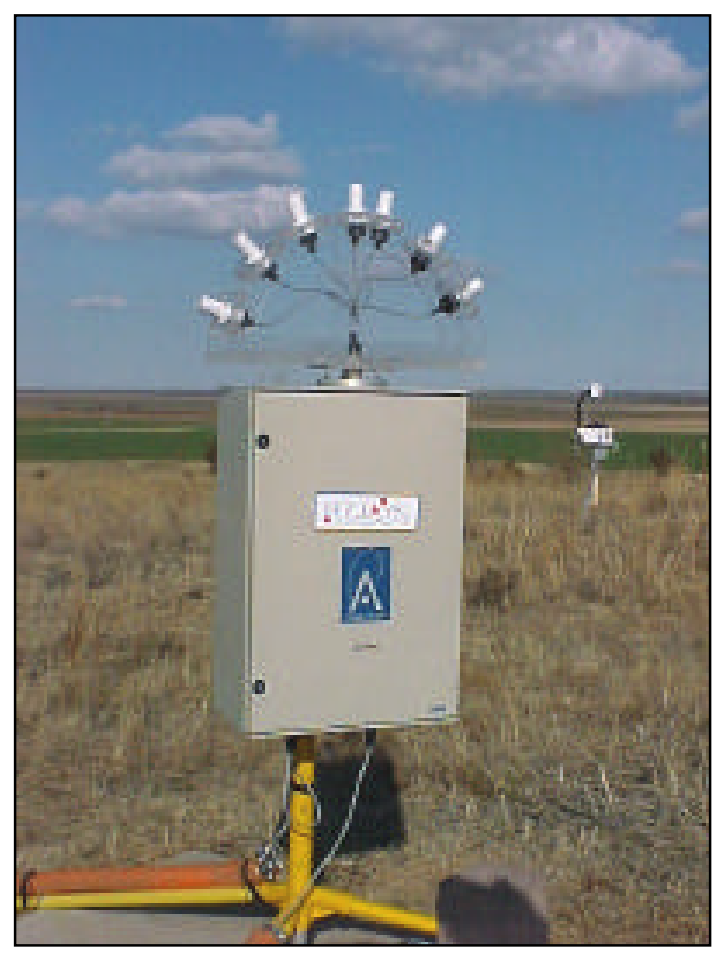

Figure 3. The Nephelo installed at the SGP central facility for the Cloudiness Intercomparison IOP (ARM photo.)

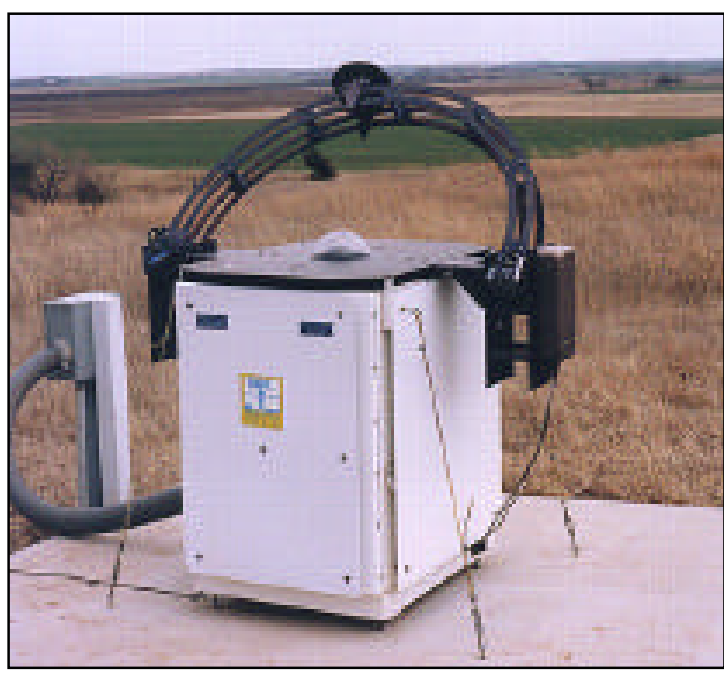

Figure 2. The currently installed whole-sky imager (WSI) at the SGP CART site central facility. The WSI is an automated instrument used to detect the presence, distribution, shape, and radiance of clouds over the entire sky. (ARM photo.)

Le Havre, France). The Nephelo uses a series of infrared detectors to yield estimates of fractional sky cover. A second instrument to be tested, developed by Dr. Joe Shaw of Montana State University, is an infrared cloud imager. This instrument was previously deployed for testing at ARM's North Slope CART site in Barrow, Alaska. The third system to be tested will be a narrow-field-of-view infrared thermometer (which infers cloud base temperature and multiple-layer clouds), operated in scanning mode rather than in the fixed vertical orientation.

Scanning with the instrument and analyzing high-frequency samples of its data will increase the sky area covered.

Collection of cloud data is not straightforward, because determination of actual cloud cover is subject to the definition of what is and is not a cloud. 
An instrument's determinations and calculations depend on its ability to detect a cloud either via collection of backscatter from a directed signal or by computer analysis of digital photographs. Verification of the data is restricted by the difficulty of the establishing a "ground truth" value. Thus, the emphasis in this IOP has to be on comparing measurements from the different instruments.

Earth's climate is directly affected by the presence and absence of clouds. However, the accuracy of computer depictions and prognostications of future climate is limited by inadequacies in the parameterization of clouds in global climate models. A high-priority ARM Program goal is to increase our understanding of the interactions between clouds and solar radiation in the atmosphere, so that this complicated duo can be incorporated accurately into computer climate models.

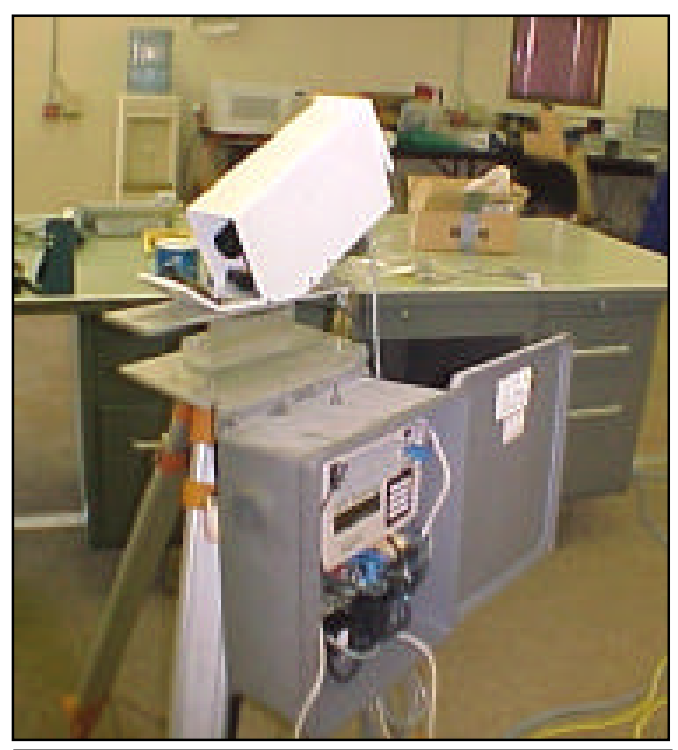

Figure 5. The scanning infrared thermometer is being prepared for deployment during the Cloudiness Inter-comparison IOP. (ARM photo.)

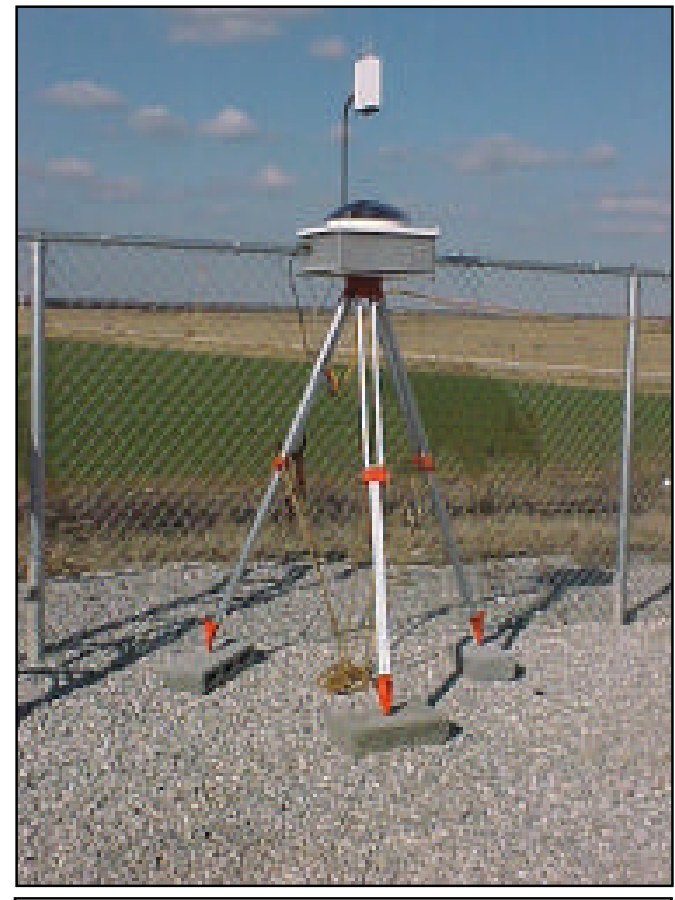

Figure 4. A second total sky imager has been deployed at the central facility to work in tandem to produce stereo, threedimensional information about the clouds over head. (ARM photo.) 